\title{
Beyond Patents: The Problems of Non-Traditional Trademark Protection for Medicines and Health Technologies
}

\author{
Irene Calboli
}

Published online: 4 December 2019

(C) Max Planck Institute for Innovation and Competition, Munich 2019

In November 2015, the United Nations Secretary General convened a High-Level Panel on Access to Health Technologies. The Panel's objective was "to propose solutions for addressing the incoherencies between international human rights, trade, intellectual property rights, and public health objectives." In a Report issued in September 2016, the Panel discussed how countries worldwide could use the flexibilities in the Agreement on Trade-Related Aspects of Intellectual Property Rights (TRIPS) to foster research and development of health technologies. Unsurprisingly, the Panel's report focused on patent law. Yet, in the Report's Annexes, it was highlighted that other IP rights, such as trademarks and copyright, can also "exert monopolistic effects in the market," and that the effects of these rights can "rival those associated with patents and with a far greater duration" due to their different terms and scope of protection. ${ }^{1}$ As a result, it was noted, more attention should be paid to these rights "to tackle the[ir] combined effects ... on the cost, distribution, and accessibility of medicines and health technologies."2

Similar to the Panel's Report, academic scholarship on access to medicines and health technologies continues to focus largely on patents and related limitations and

\footnotetext{
1 U.N. Secretary-General's High-Level Panel on Access to Medicines, Promoting Innovation and Access to Health Technologies, Annex by Professor Ruth Okediji, Member of the High- Level Panel, at 60 (Sept. 14, 2016).

2 Id.
}

I thank John Yoon for research assistance. This editorial continues the conversation on non-traditional trademarks that I started in "Chocolate, Fashion, Toys, and Cabs: the Misunderstood Distinctiveness of Non-Traditional Trademarks" 49 IIC 1 (2018) https://doi.org/10.1007/s40319-017-0667-x.

Irene Calboli is Professor of Law at Texas A\&M University School of Law, Fort Worth, USA; Haken Distinguished Fellow, Hanken School of Economics, Helsinki, Finland; and Academic Fellow, School of Law University of Geneva, Geneva, Switzerland.

I. Calboli $(\bowtie)$

Professor of Law, Texas A\&M University School of Law, Fort Worth, USA

e-mail: icalboli@law.tamu.edu 
exceptions to patent rights. ${ }^{3}$ This is of course understandable, considering the primary role patents play in the research and development and the exclusive market distribution of medicines and health technologies. It is precisely the strength of patent protection that is the basis of the industry's attempts to seek secondary patents on variations of original medicines. Examples of variations include new forms of release, new dosage, and new forms and combinations of the originals. Yet, the industry is not foreign to the use of other types of IP rights, particularly trademark rights in the form of non-traditional trademark protection. In the past decades, several lawsuits have taken place regarding claims of trademark infringement, unfair competition, and passing off related to the shapes, colors, packaging, and other product features of medicines and medical devices. ${ }^{4}$ As trademark protection can last in perpetuity - so long as the mark continues to be (at times minimally) used in the course of trade - trademarks become an additional useful tool in the industry's IP strategy, even though this protection cannot extend to active ingredients and functional aspects of products after the expiration of the patent term.

A search of existing registrations related to health technologies in national trademark registries reveals that many companies own registrations for nontraditional trademarks, mostly shapes, colors, and combinations thereof, for their pharmaceutical and medical devices. A few examples just in the United States include: hepatitis C drugs (Gilead Sciences), ${ }^{5}$ general pill (Gilead sciences), ${ }^{6} \mathrm{HIV}$ pills (Gilead Sciences), ${ }^{7}$ asthma inhalers (Teva Respiratory), ${ }^{8}$ respiratory inhalers (Glaxo Group), ${ }^{9}$ disposable pharmaceutical vial adapters (West Pharma), ${ }^{10}$ medical gowns (Avent), ${ }^{11}$ medical gloves (Avent), ${ }^{12}$ and of course, the famous "blue pill," also known as Viagra (Pfizer). ${ }^{13}$ Similar searches show the same results in the European Union, the United Kingdom, Germany, Switzerland, and so on, even

\footnotetext{
${ }^{3}$ For an excellent contribution on non-traditional trademarks and access to health technologies, see Arule George Scaria and Kavya Susan Mammen, "Non-Traditional Trademarks in the Pharmaceutical Sector: Non-Traditional Barriers to Access to Medicines?", in The Protection of Non-Traditional Trademarks: Critical Perspectives p. 271 (Irene Calboli and Martin Senftleben eds., 2018).

4 Id.

5 Registration No. 5,018,105, U.S. (diamond shape, light-orange color, and identification number of medicine); Registration No. 5,018,106, U.S. (oval shape, light-yellow color, and identification number of medicine).

${ }^{6}$ Registration No. 2,679,181, U.S. (almond shape and color blue of medicine).

7 Registration No. 5,030,567, U.S. (oblong shape and color blue of medicine).

${ }^{8}$ Registration No. 5,435,196, U.S. (colors yellow and white of inhaler).

9 Registration No. 2,625,335, U.S. (orange color for body, and peach color for cap of inhaler); Registration No. 5,614,245, U.S. (color purple of inhaler); Registration No. 3,812,561, U.S. (round design, purple color, white color, and wave patterns of inhaler).

${ }^{10}$ Registration No. 5,860,032, U.S. (three-dimensional configuration of cylindrical shapes with curved edges).

11 Registration No. 5,619,321, U.S. (gray color of gown).

12 Registration No. 5,278,439, U.S. (colors green, Pantone number 7488U for gloves).

13 Registration No. 2,593,407, U.S. (diamond shape and color blue of medicine).
} 
though the same marks are not always registered in every country and, at times, registered marks have been cancelled or revoked in some jurisdictions. ${ }^{14}$

The purpose of this Editorial is to highlight the need for a larger conversation between academics, policymakers, related industry, and other stakeholders over the use and abuse of trademark protection and non-traditional trademarks in the area of medicines and health technologies. Certainly, whether it applies to shoes, bags, or medicines, the protection of non-traditional trademarks remains controversial due to the potential negative impact of these marks on market competition and freedom of expression. ${ }^{15}$ Non-traditional trademarks are "signs" that frequently comprise entire products or relevant features of products. ${ }^{16}$ The protection of these marks can easily lead to undesirable monopolies on shapes, colors, combinations of colors, sounds, etc., as several judicial decisions (some against and some in favor of these marks) have showcased. ${ }^{17}$ Yet, while granting perpetual protection as trademarks to Louboutin's red-sole shoes or Hermes' Birkin bags is certainly problematic for long-term market competition, the encroachment of non-traditional trademark protection is especially worrisome when it applies to medicines and health technologies due to the particularly damaging effects that overlapping trademark and patent protection can have on access to generic medicines and health therapies. It is costly and complicated enough for generic companies to have to face the threat of patent litigation without adding the costs and complications of trademark litigation. Moreover, most litigation resolves with out-of-court settlements. These settlements at times include licensing agreements, but the terms of the settlements remain confidential. Accordingly, granting non-traditional trademark protection to medicines and health technologies not only incentivizes additional litigation. It also may incentivize unnecessary, and costly, licensing as part of out-of-court settlements.

Because of their "non-traditional" nature, national IP offices, including the EU IP Office (EUIPO), and national courts have frequently looked at non-traditional trademarks with skepticism. ${ }^{18}$ Still, to date, no IP office or court has explicitly and officially denounced the negative policy impact the combined effect of multiple IP protections can have in general, and as it applies to medicines and health technologies in particular. Moreover, despite the fact that some applications for nontraditional marks have been refused, and a few others may have been cancelled or revoked after registration, non-traditional trademarks continue to be routinely registered across various continents, and the trend is to further facilitate the

\footnotetext{
${ }^{14}$ For an example of a mark that has been revoked in the EU, see Glaxo Wellcome UK Ltd \& Anr v. Sandoz Ltd [2017] EWCA Civ 335 (holding Glaxo's EU trademark 3890126 for purple color for inhalers to be invalid). The mark is still valid in the U.S. See supra note 9.

15 In general, see the contributions published in Irene Calboli and Martin Senftleben (eds.), The Protection of Non-Traditional Trademarks: Critical Perspectives (2018).

16 See, e.g., Registration No. 3,361,597, U.S. (Louboutin red-sole shoes); Registration No. 3,939,358, U.S. (shape of Hermes Birkin bags); Registration No. 3,282,846 U.S. (Cartier watch with square face); Registration No. 915,325, U.S. (Christian Dior perfume bottle design); Registration No. 1,643,625, U.S. (Louis Vuitton leather bag shape).

17 See Irene Calboli and Martin Senftleben, supra note 15.

${ }^{18} \mathrm{Id}$.
} 
registration of these marks worldwide. ${ }^{19}$ Case law in this area also remains inconsistent and it is difficult to predict how a court will rule on the validity of these marks. The survey of judicial decisions across various jurisdictions in the past years indicates that courts tend to be very technical in their decisions. Notably, courts seem to focus on a detailed analysis of the requirement (the presence or lack thereof) of trademark distinctiveness, the presence or absence of an absolute ground for refusal or cancellation of the registration, and the specific facts of each case. ${ }^{20}$ In particular, the key factor in the final result of these disputes seems to be how well litigants prepare their case, and how well-supported their case is by the evidence presented. Rarely do courts address the policy concerns of this protection.

Yet again, non-traditional trademark protection has serious policy implications in general, and the acceptance of this protection becomes particularly worrisome when it applies to medicines and health technologies, as non-traditional trademarks may delay or altogether block access to these therapies after the patents' expiration.

In particular, as noted by scholars, empirical studies have proven that some patients might be reluctant to take generic medicines if the color and appearance are different than their branded counterpart. ${ }^{21}$ Similarly, studies have suggested that medical service providers need to invest substantial time to reassure patients when they prescribe different-looking generic medicines as some patients doubt the efficacy of these medicines if those previously prescribed (under the patent term) appeared different. Studies have additionally addressed the relationship between the aesthetic features of medicines and the placebo effects - the "nonspecific, psychological, or psychophysiological therapeutic effect produced by a placebo" ${ }^{22}$ - and found a link with the size, shape, and color of the medicines. $^{23}$ These findings are not new. In the early 1970s, the Court of Appeal in the UK noted that patients may be confused if the generic medicines were a different color combination. ${ }^{24}$ In the early 1980s, the United States Supreme Court held that competitors might be free to copy a medicine's color if the color served to identify the kind of medicine as "some patients commingle medications in a container and rely on color to differentiate one from another." ${ }^{25}$ Despite these early warnings, as I mentioned above, registration of non-traditional trademarks for medicines and health technologies is nonetheless a common occurrence in the U.S., the EU, and many countries today.

A recent judicial decision in the UK reflected again the importance of this topic. In Glaxo Wellcome UK Limited and Anor v. Sandoz Limited \& Ors, Lord Justice Arnold dismissed the claims for passing off brought by GlaxoSmithKline (GSK), the producers of a purple inhaler, against generic manufacturer Sandoz for having

\footnotetext{
19 Id.

20 Id.

21 See Scaria and Mammen, supra note 4, at 280 (citing relevant studies).

${ }^{22}$ Id. (citing Arthur K. Shapiro and Elaine Shapiro, “The Placebo: Is It Much Ado About Nothing?", in The Placebo Effect p. 12 (Anne Harrington ed., 1999)).

23 Id.

24 Hoffmann-La Roche \& Co. A.G. v. D.D.S.A. Pharm. Ltd., [1972] RPC 1, 21 (CA).

25 Inwood Laboratories Inc. v. Ives Laboratories, Inc., 456 U.S. 844, 850, 853 (1982).
} 
copied the color purple for its own inhaler that differed in shape and operation. ${ }^{26}$ GSK's EUTM for the same color was revoked in summary judgment and the trial focused on the passing off claims related to the alleged misappropriation of the color. Justice Arnold reasoned there was no misrepresentation towards the products' origin as the inhalers were prescription-based therapy and doctors prescribed inhalers based on ingredients, not the color of the inhaler. He also rejected the claim for misrepresentation of the products' equivalence for healthcare professionals and patients based on lack of evidence. However, while GSK did not succeed on its passing-off claim in the UK, and lost the mark in the EU, the U.S. mark for the same color inhaler remains alive. ${ }^{27}$ This highlights an additional layer of complexity in the debate. As trademark rights remain territorial, the rejection of protection in one country may not translate into rejections in other jurisdictions. Moreover, the terms of licensing agreements often apply to "worldwide license." Thus, companies may be bound by the terms of these agreements in multiple jurisdictions based on the valid trademark rights in one country, even though the same mark may have been revoked or not been granted in another country.

In conclusion, non-traditional trademarks offer an additional tool to create exclusive rights on medicines and health technologies beyond the scope and term of patent protection. This can lead to unnecessary and complex litigation, which can deter generic companies and in turn negatively affects access to healthcare. This extra layer of exclusivity is problematic even if these rights are not vested in the active ingredients of the medicines or the technology of the devices. Trademarks may not protect the core subject matter of the treatment, yet they still constitute a barrier to access to medicines and health technologies. In a world where generic manufactures may already struggle to find market access due to additional patent protection through secondary patents and similar strategies, the law should not incentivize additional barriers in the form of non-traditional trademarks. Certainly, the shapes, colors, and other characteristics of medicines and medical devices could be found to be distinctive - particularly since the manufacturers could use these signs exclusively during the patent term. Still, these signs often become functional to the effective delivery of the treatment. This type of functionality may not be the traditional type of utilitarian functionality, yet it is a therapeutically-based functionality, as patients have become used to these signs as a fundamental part of their treatment. Moreover, even when these signs may simply be aesthetic additions to products otherwise prescribed by doctors based on ingredients and other technical features, they make the products more appealing and thus are aesthetically functional. For all these reasons, these signs should not be protected as trademarks.

Publisher's Note Springer Nature remains neutral with regard to jurisdictional claims in published maps and institutional affiliations.

\footnotetext{
${ }^{26}$ Glaxo Wellcome UK Ltd \& Anor v. Sandoz Ltd \& Ors [2019] EWHC 2545 (Ch) (04 October 2019).

27 Registration No. 3,812,561, U.S. (round design, purple color, white color, and wave patterns of inhaler).
} 